\title{
PENINGKATAN KEMAMPUAN PERCAKAPAN DAN MENGEJA BILANGAN ANGKA DALAM BAHASA INGGRIS PADA SISWA SD DAN SMP DI RW 09 KELURAHAN SAGULUNG KOTA - KOTA BATAM
}

\section{ENHANCING CAPABILITY AND ENJOYING NUMBER OF NUMBERS IN ENGLISH PRIMARY SCHOOL STUDENTS AND JUNIOR HIGH SCHOOL STUDENTS IN RW 09 VILLAGE OF SAGULUNG KOTA - BATAM CITY}

\author{
Cahyo Budi Santoso \\ (Program Studi Akuntansi, Fakultas Ekonomi, Universitas Riau Kepulauan, Batam, Indonesia) \\ lcafana07@gmail.com
}

\begin{abstract}
Abstrak
Tujuan pengabdian ini adalah untuk mengetahui bagaimana meningkatan kemampuan percakapan dan mengeja bilangan angka dalam Bahasa Inggris pada siswa SD dan SMP di RW 09 Kelurahan Sagulung Kota - Kota Batam. Metode yang digunakan dalam pengabdian ini adalah metode langsung yaitu menuntun anakanak mengucapkan kata per kata, kalimat per kalimat dan melatih kemahiran siswa dalam mengucapkan Bahasa Inggris dengan baik dan benar. Hasil yang diperoleh Anak-anak mulai mengerti materi dasar yang diberikan (mengeja abjad dan angka dalam Bahasa Inggris), mengetahui pentingnya Bahasa Inggris dalam kehidupan sehari-hari, berani berkomunikasi / mampu mengenalkan dirinya secara sederhana menggunakan Bahasa Inggris.
\end{abstract}

Kata Kunci : kemampuan, metode langsung, mengeja, bahasa

\begin{abstract}
The purpose of this dedication is to know how to improve the conversation ability and spell the number of numbers in English in elementary and junior high school students in RW 09 Sagulung Kota-Batam City. The method used in this devotion is the direct method of guiding the children to pronounce words per word, sentences per sentence and train students' skills in speaking English well and correctly. The results obtained Children begin to understand the basic material given (spelling the alphabet and numbers in English), know the importance of English in everyday life, daring to communicate / able to introduce themselves simply using English.
\end{abstract}

Keywords : ability, direct method, spelling, language

\section{PENDAHULUAN}

Kavling Sekarwangi RW 09 adalah sebuah daerah urban di Kota Batam tepatnya berada di Kelurahan Sagulung Kota - Kecamatan Sagulung. Letak kavling ini sangat strategis karena berjarak $\pm 1 \mathrm{~km}$ dari Kantor Kelurahan Sagulung Kota, $\pm 1 \mathrm{~km}$ dari sekolah yaitu SDN 004 Sagulung dan SDN 006 Sagulung dan dekat/menjadi akses menuju (dari dan ke) kawasan 
industri Latrade dan kawasan industri Bintang. Infrastuktur yang ada seperti jalan utama telah diaspal, sebagian jalan lingkungannya ada yang telah diaspal dan sebagiannya lagi masih dalam berupa jalan cor semen, juga memiliki fasilitas umum yang diperuntukan untuk sarana ibadah (masjid), sarana pendidikan (Taman Pendidikan Al Quran), tempat pertemuan warga (balai warga) dan sarana olahraga (lapangan badminton dan lapangan volley).

Jumlah penduduk di Kavling Sekarwangi RW 09 terdiri dari 108 KK dan 418 jiwa. Mayoritas penduduknya berasal dari daerah yang sama (Jawa), dan 96\% beragama Islam. Ratarata tingkat pendidikan penduduknya SMA. Yang sedang menempuh pendidikan dari tingkat TK/Play Group/PAUD sampai dengan Perguruan Tinggi sebanyak 190 orang atau 45\% nya sedang sekolah. Mayoritas penduduknya bekerja sebagai buruh 45\%, dan 55\% sisanya terdiri dari pedagang (18\%), berkebun (18\%), penyedia jasa (12\%), PNS (6\%) dan pengrajin (1\%).

Suasana kehidupan di Kavling Sekarwangi keadaanya tidak jauh berbeda dengan suasana kehidupan masyarakat urban pada umumnya yaitu individualis, kurang peduli pada orang lain, sangat berorientasi pada waktu, kepentingan, kedudukan dan status. Namun demikian suasana rukun dan guyup masih sangat terasa. Dengan mayoritas penduduknya berasal dari satu daerah (suku) dan agama yang sama (islam), sehingga masyarakatnyapun mudah diarahkan dan diatur.

Dengan beragamnya kepentingan dan tingkat persaingan hidup di perkotaan yang tinggi, mendorong setiap penduduknya sibuk melakukan berbagai macam aktifitas. Mulai dari bekerja, berdagang, sekolah, buka usaha rumahan seperti kripik singkong, depot air, kerajinan tangan, budidaya tanaman sayuran dll. Para orang tua dan dewasa sibuk dengan mencari/meningkatkan pendapatan keluarga. Para anak-anak sibuk dengan aktivitas sekolah dan bermain. Dengan aktivitas yang begitu padat, tentunya membutuhkan kondisi stamina tubuh yang prima, sehat jasmani dan rohani. Untuk menjaga kondisi tubuh tetap prima dan sehat dapat dilakukan dengan berbagai macam kegiatan misalnya olahraga yang teratur, menjaga pola makan hidup sehat, mengikuti kegiatan keagamaan maupun kerohanian.

Hasil observasi dilapangan, Kavling Sekarwangi RW 09 mempunyai sarana fasilitas umum (fasum) untuk lapangan olahraga dan sarana pendidikan yang memadai. Usaha rumahan yang dijalankan sudah lama dimulai, namun hingga saat ini perkembangan usaha belum menunjukkan perkembangan yang cukup signifikan. Setelah pulang sekolah, khususnya pada hari Sabtu dan 
Minggu anak-anak pada asyik bermain yang kurang bermanfaat padahal mereka mengalami kesulitan dalam pelajaran Matematika dan Bahasa Inggris disekolahnya. Pada hari Sabtu dan Minggu sarana pendidikan yang ada (TPA) tidak dipakai (kosong tidak ada jadwal). Masyarakatnya khusus ibu-ibu sebenarnya sudah ada keinginan sejak lama untuk melakukan kegiatan olah raga massal secara rutin. Ingin usahanya yang dijalankan cepat berkembang dan maju, tidak stagnan seperti saat ini. Ingin punya usaha lainnya sehingga bisa membantu meningkatkan pendapatan keluarga. Para orang tua ingin agar anak-anaknya meningkat prestasinya/pengetahuannya dalam pelajaran Matematika dan Bahasa Inggris.

Bahasa Inggris adalah bahasa pengantar internasional. Menguasainya menjadikan modal untuk kesukesan seseorang bersaing dalam dunia globalisasi. Agar terampil berbahasa inggris yang baik dan benar, dibutuhkan jam terbang latihan yang tinggi, dibutuhkan mental berani dan waktu yang memadai. Memperbanyak latihan berbahasa inggris dan membentuk mental berani siswa untuk berbahasa inggris tidak cukup hanya diasah bangku sekolah namun juga perlu dilatih dan diasah diluar jam sekolah, baik mellaui bimbingan belajar maupun privat.

Mengenalkan diri sendiri dan berhitung (menyebutkan/membilang angka) adalah bagian dari kehidupan sehari-hari. Dalam era globalisasi seperti saat ini, sangat diperlukan kemampuan mengenalkan diri sendiri dan berhitung (menyebutkan/membilang) angka dalam bahasa inggris.

\section{METODOLOGI}

\section{Bentuk Dan Teknis Kegiatan}

Pendampingan dalam peningkatan kemampuan percakapan dan mengeja bilangan angka dalam Bahasa Inggris pada siswa SD dan SMP di RW 09 Kelurahan Sagulung Kota - Kota Batam dilaksanakan dalam bentuk memberikan pelajaran Bahasa Inggris dengan metode langsung (direct method). Metode ini menuntun anak-anak mengucapkan kata per kata, kalimat per kalimat dan melatih kemahiran siswa dalam mengucapkan Bahasa Inggris dengan baik dan benar.

Ciri- ciri metode ini antara lain :

1. Tujuan dasar yang diharapkan oleh metode ini adalah mengembangkan kemampuan siswa untuk berpikir dengan bahasa asing bukan dengan bahasa ibu siswa. 
2. Hendaklah pembelajaran bahasa asing dengan menggunakan bahasa asing tidak menggunakan lain sebagai medianya.

3. Percakapan antar individu merupakan bentuk pertama dan yang umum untuk digunakan dalam masyarakat, sehingga pada awal pembelajaran bahasa asing hendaknya percakapan mereka menggunakan kosakata dan susunan kalimat sesuai dengan maksud dan tujuan belajar siswa.

4. Diawal pembelajaran siswa dikondisikan untuk mendengarkan kalimat-kalimat sempurna dan mempunyai makna yang jelas, sehingga siswa mampu dan mudah memahaminya.

5. Pengembangan ketrampilan kognitif siswa seperti kemampuan analogis dan analisis merupakan hal yang tidak boleh menyibukkan perhatian pemakai model ini.

6. Perhatian metode ini lebih banyak pada pengembangan kemampuan siswa untuk berbicara dibandingkan pada aspek yang lain.

7. Materi pelajaran pertama- tama diberikan kata demi kata, kemudian struktur kalimat.

8. Gramatika diajarkan hanya bersifat sambil lalu, dan siswa tidak dituntut menghapal rumus- rumus gramatika, tapi yang utama adalah siswa mampu mengucapkan bahasa asing secara baik.

9. Dalam proses pengajaran senantiasa menggunakan alat bantu (alat peraga) baik alat peraga langsung, tidak langsung (benda tiruan) maupun peragaan melalui symbolsymbol atau gerakan- gerakan tertentu.

10. Setelah masuk kelas, siswa atau anak didik benar- benar dikondisikan untuk menerima dan bercakap- cakap dalam bahsa asing dan dilarang menggunakan bahasa lain.

11. Materi pelajaran terdiri dari kata- kata dan struktur kalimat yang banyak digunakan sehari- hari.

12. Gramatika diajarkan dengan melalui situasi dan dilakukan secara lisan bukan dengan cara menghafal aturan- aturan gramatika.

13. Arti yang konkrit diajarkan dengan menggunakan benda- benda sedangkan arti yang abstrak melalui asosiasi

14. Banyak latihan- latihan mendengar dan menirukan dengan tujuan agar dapat dicapai penguasaan bahasa secara otomatis. 
15. Aktivitas belajar banyak dilakukan di dalam kelas.

16. Bacaan mula- mula diberikan secara lisan.

17. Sejak permulaan murid dilatih untuk "berfikir dalam bahasa asing".

18. Peserta didik diberikan kesempatan untuk berlatih dengan cara tanya jawab dengan guru/ sesamanya.

Keunggulan metode langsung :

1. Siswa termotivasi untuk dapat menyebut dan mengerti kata- kata dan kalimat dalam bahasa asing yang diajarkan gurunya, apalagi guru menggunakan alat peraga dan macammacam media yang menyenangkan.

2. Siswa dapat dengan mudah menangkap symbol- symbol bahasa asing yang diajarkan gurunya karena metode ini biasanya guru mula-mula mengajarkan kata- kata dan kalimatkalimat sederhana yang dapat dimengerti dan diketahui siswa dalam bahasa sehari- hari misalnya (pena, pensil, bangku, meja, dll)

3. Metode ini menarik minat siswa, karena sudah merasa senang/ tertarik dan merasa tidak sulit. Metode ini relative banyak menggunakan berbagai macam alat peraga, apakah video film, kaset, dan berbagai media / alat peraga yang dibuat sendiri.

4. Siswa memperoleh pengalaman langsung dan praktis, sekalipun mula- mula kalimat yang diucapkan itu belum dimengerti dan dipahami sepenuhnya.

5. Alat ucap(lidah) siswa/anak didik menjadi terlatih menerima ucapan- ucapan yang semula sering terdengar dan terucap.

6. Cocok dan sesuai bagi tingkat- tingkat linguistic para siswa.

Kelemahan metode langsung :

1. Pengajaran dapat menjadi pasif, jika guru tidak dapat memotivasi siswa, bahkan mungkin sekali siswa merasa jenuh dan merasa dongkol karena kata- kata dan kalimat yang dituturkan gurunya itu tidak pernah dapat dimengerti, karena memang guru hanya menggunakan bahasa asing tanpa diterjemahkan kedalam bahasa anak. 
2. Pada tingkat permulaan kelihatannya metode ini terasa sulit diterapkan, karena siswa belum memiliki bahan (perbendaharaan kata- kata) yang sudah dimengerti.

3. Meskipun pada dasarnya metode ini guru tidak boleh menggunakan bahasa sehari- hari dalam menyampaikan bahan pelajaran bahasa asing tapi pada kenyataannya tidak selalu konsisten demikian, guru terpaksa misalnya menerjemahkan kata-kata sulit bahasa asing itu kedalam bahasa anak didik.

4. Penguasaan bahasa yang sempurna biasanya sukar bisa dicapai.

5. Sukar sekali diterapkan pada kelas yang besar.

6. Memerlukan pengajaran yang memiliki kemampuan aktif dalam bahasa asing yang diajarkan.

7. Dengan menggunakan hanya bahasa asing kerapkali banyak waktu terbuang, sebab bahasa ibu kadang lebih efektif dipakai untuk menjelaskan berbagai macam aspek bahasa.

8. Karena tidak menggunakan bahasa ibu maka memerlukan lebih banyak keseriusan sehingga memerluka banyak waktu.

9. Sangat membutuhkan guru yang terampil dan fasih.

10. Sukar menyediakan berbagai kegiatan yang menarik dan bersifat situasi didalam kelas.

\section{PEMBAHASAN}

Kegiatan pendampingan ini dilaksanakan selama 2 hari, dengan materi yang diberikan untuk siswa tingkat SD mengenai pengejaan kata dan angka ratusan dalam Bahasa Inggris, sedangkan untuk siswa tingkat SMP mengenai perkenalan diri (greeting and introducing) dan angka ribuan hingga jutaan.

Maksud dan tujuan pendampingan ini adalah untuk melatih anak-anak mulai dari perkenalan, sapaan, angka, dan abjad yang sering digunakan dalam percakapan sehari-hari. Melalui kegiatan ini diharapkan anak-anak mulai termotivasi dan semangat untuk belajar Bahasa Inggris sejak dini. Sehingga mereka tidak asing lagi dengan salah satu bahasa internasional yang sering digunakan di berbagai belahan dunia.

Pada awal sebelum dilakukan pendampingan, kondisi siswa baik tingkat SD maupun tingkat SMP, kurang mampu berbicara dan menyebutkan angka dalam Bahasa Inggris. Beberapa 
faktor penyebabnya karena tidak berani atau kurang percaya diri untuk tampil didepan umum, kurang menguasai kosa kata dan angka yang sering digunakan dalam percakapan sehari-hari.

Metode yang digunakan dalam kegiatan pembelajaran Bahasa Inggris ini adalah direct method. Metode ini dipilih karena dianggap metode yang paling sesuai dan tepat untuk mencapai tujuan pembelajaran. Dalam metode ini, selama kegiatan mengajar berlangsung, guru menggunakan bahasa yang diajarkan, sedangkan bahasa siswa tidak boleh digunakan. Langkahlangkahnya yaitu memilih topik yang sesuai dengan taraf kemampuan peserta didik. Materi disesuaikan dengan taraf perkembangan dan kemampuan anak didik, dan dimulai dengan katakata yang dapat dimengerti anak didik. Kemudian guru mengucapkan kata-kata atau kalimat yang sesuai dengan tingkat kemampuan anak didik dengan menggunakan alat peraga bila diperlukan sedangkan arti yang abstrak dijelaskan melalui asosiasi. Dan sejak awal peserta didik dilatih cara berfikir menurut bahasa yang diajarkan bukan bahasa ibu siswa.

Adapun tahapan pembelajaran dengan metode langsung (direct method) adalah sebagai berikut :

1. Membentuk kelompok-kelompok belajar, yang setiap kelompoknya terdiri dari 4-5 anak-anak dari berbagai usia.

2. Pengajar menuliskan materi yang dipelajari di papan tulis.

3. Pengajar memberikan contoh, misal pengucapan kata/kalimat dengan jelas dan benar atau pun mengenalkan diri dalam Bahasa Inggris

4. Pengajar meminta anak-anak mengikuti apa yang diajarkan dengan suara yang jelas dan benar

5. Dalam proses pembelajaran dilakukan tanya jawab beserta dengan game agar semua anak-anak aktif mengikuti kegiatan.

6. Diakhir materi, pengajar memberikan pertanyaan secara acak atas materi yang telah diberikan.

7. Diakhir kegiatan,dilakukan evaluasi berupa test

Secara teknis dilapangan, Misnawati Purba berperan sebagai Koordinator bertugas merancang, menyusun, membagi dan memberikan pengarahan kepada tim pengajar Bahasa Inggris. 


\section{Materi yang di berikan:}

SD : Alphabet, Spelling (mengeja), Number dan perkenalan sederhana.

Contoh:

D E N I S : di-i-en-ai-es

$\mathrm{A}(e i) \mathrm{B}(b i) \mathrm{C}(s i) \ldots$

$20:$ twenty

250: two hundred fifty

SMP : Greeting \& introducing, number (jutaan)

Contoh:

$\begin{array}{ll}A & : \text { Hello, how are you? } \\ B & \text { : I am fine, thanks. } \\ A & : \text { What is your name? } \\ B & : \text { My name is Sasha. } \\ A & : \text { Where do you come from? } \\ B & : \text { I come from Jakarta. } \\ A & : \text { Where do you live? } \\ B & : \text { I live in Garut. } \\ A & : \text { Who do you live with? } \\ B & : \text { I live with my family. } \\ A & : \text { How old are you? } \\ B & : \text { I am fifteen years old. }\end{array}$

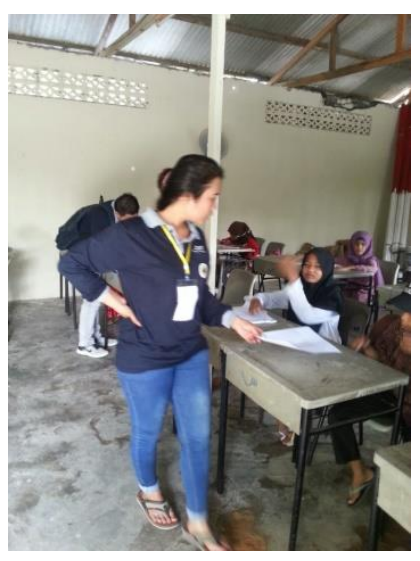

7.444.129: Seven million four hundred forty four thousand a hundred and twenty nine
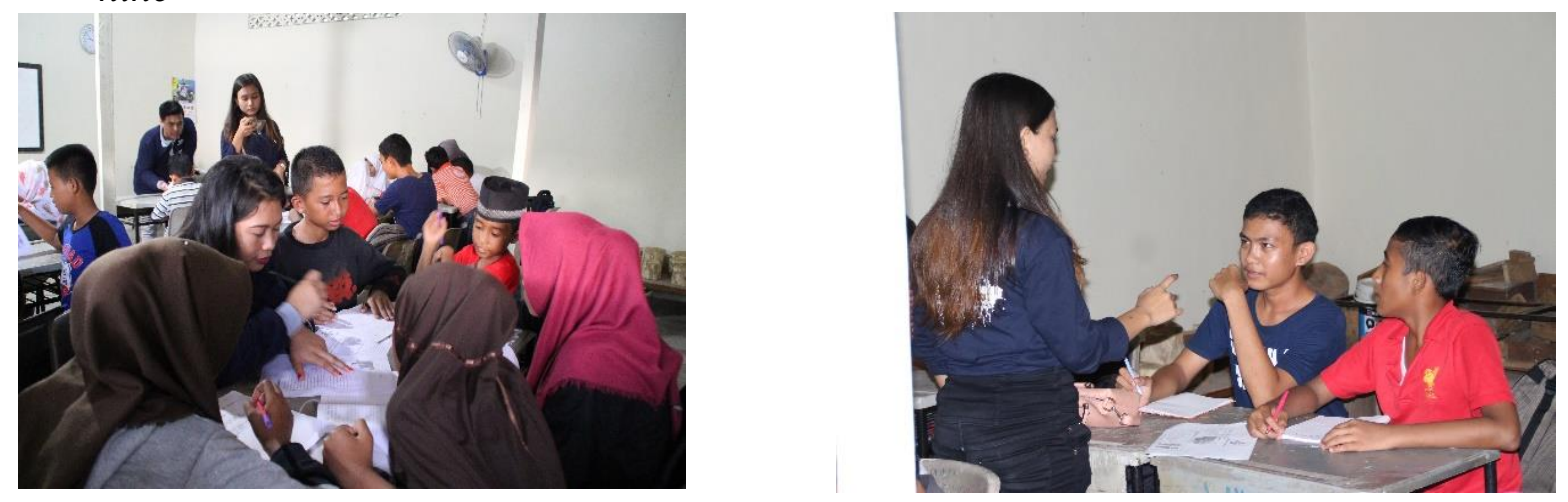

Gambar 3.1 Suasana Pembelajaran

\section{Hasil yang dicapai dan tindaklanjut}


Anak-anak mulai mengerti materi dasar yang diberikan (mengeja abjad dan angka dalam Bahasa Inggris), mengetahui pentingnya Bahasa Inggris dalam kehidupan sehari-hari, berani berkomunikasi / mampu mengenalkan dirinya secara sederhana menggunakan Bahasa Inggris. Walaupun belum menguasai materi yang diberikan sepenuhnya namun siswa telah memiliki keberanian dan semangat berbicara didepan umum mengenalkan diri sendiri (introduction your self).

\section{KESIMPULAN DAN SARAN}

\section{Kesimpulan}

Pengabdian masyarakat melalui kegiatan pendampingan dalam peningkatan kemampuan percakapan dan mengeja bilangan angka dalam Bahasa Inggris pada siswa SD dan SMP di RW 09 Kelurahan Sagulung Kota - Kota Batam mampu meningkatkan kemampuan mental para peserta didik untuk berani tampil berbicara di muka umum dengan menggunakan pengantar internasional (Bahasa Inggris).

Program pendampingan dapat diselenggarakan dengan baik dan berjalan dengan lancar sesuai dengan rencana kegiatan yang telah disusun meskipun belum semua peserta pendampingan menguasai dengan baik materi yang disampaikan. Kegiatan ini mendapat sambutan sangat baik terbukti dengan keaktifan peserta mengikuti pendampingan.

\section{Saran}

Berdasarkan evaluasi yang telah dilakukan dapat diajukan beberapa saran sebagai berikut:

1. Waktu pelaksanaan kegiatan pengabdian perlu ditambah agar tujuan kegiatan dapat tercapai sepenuhnya, tetapi dengan konsekuensi penambahan biaya pelaksanaan. Oleh karena itu biaya PPM sebaiknya tidak sama antara beberapa tim pengusul proposal, mengingat khalayak sasaran yang berbeda pula.

2. Adanya kegiatan lanjutan yang berupa pendampingan sejenis selalu diselenggarakan secara periodik seperti pendampingan dalam peningkatan kemampuan pada pelajaran Matematika dalam berhitung dan menghafal perkalian. 


\section{REFERENSI}

Izzan, Ahmad. 2009. Metodologi Pembelajaran Bahasa Arab. Bandung : Humaniora.

Sumardi, Muljanto. 1974. Pengajaran Bahasa Asing. Jakarta : Bulan Bintang.

Anshor, Ahmad Muhtadi. 2009. Pengajaran Bahasa Arab. Yogyakarta : Penerbit TERAS.

Hamid, Abdul. Baharudin, Uril dan Musthofa, Bisri. 2008. Pembelajaran Bahasa Arab. UINMalang Press. 